\title{
Materials Science Challenges in Radiocarbon Dating: The Case of Archaeological Plasters
}

\author{
ELISABETTA BOARETTO ${ }^{1,3}$ and KRISTIN M. PODUSKA ${ }^{2,4}$ \\ 1.-Weizmann Institute Max Planck Center for Integrative Archaeology, D-REAMS Radiocarbon \\ Laboratory, Weizmann Institute of Science, Rehovot 76100, Israel. 2.-Department of Physics and \\ Physical Oceanography, Memorial University of Newfoundland, St. John's, NL A1B 3X7, Canada. \\ 3.—e-mail: elisabetta.boaretto@weizmann.ac.il.4.—e-mail:kris@mun.ca
}

\begin{abstract}
Structural, compositional, and isotopic characterization techniques are critically important to help identify pristine materials that are suitable for accurate and precise radiocarbon dating. Lime plasters, cements, and mortars are ideal materials for establishing firm and secure dates in the archaeological record as human-constructed living surfaces and installations. However, the often complex composite structures of plasters and their susceptibility to diagenetic processes have impeded the development of a reliable and reproducible method to identify the best specimens for dating. In this article we present an overview of the plaster production process and the radiocarbon dating method. We explain how material characterization techniques and radiocarbon dating can be integrated to make progress toward the ultimate goal of relating radiocarbon concentrations with environmental, sample preparation, and/or diagenetic conditions in which the plaster existed. A key aspect of this strategy relies on implementing material characterization techniques in the field, during an excavation, to help establish the archaeological context in which datable material is recovered.
\end{abstract}

\section{THE INTERSECTION OF RADIOCARBON DATING AND MATERIALS SCIENCE}

Radiocarbon $\left({ }^{14} \mathrm{C}\right)$ dating is one of the cornerstones of modern scientific archaeology because it provides an absolute date of archaeological record. It has been widely used as a secure scientific method to fix absolute times for relative archaeological chronologies, which are typically based on typological changes of excavated materials such as ceramics and tools. ${ }^{1}$ The precision and accuracy of radiocarbon dating depend not only on the analytical methodology, but also, importantly, on the archaeological context in which the datable material was recovered. ${ }^{2,3}$ Although it is not often recognized, materials science plays a very important role in radiocarbon dating for sample screening, purification, and characterization. ${ }^{4}$

Radiocarbon dating is usually applied to organic biological materials, such as wood, seeds, and collagen, to determine the time at which a plant, animal, or person died. ${ }^{1}$ This is because an organism stops exchanging $\mathrm{CO}_{2}$ with the atmosphere when it dies, which prevents further intake of cosmogenically produced ${ }^{14} \mathrm{C}$. With a half-life of just under 6000 years, this makes ${ }^{14} \mathrm{C}$ isotope levels ideal for dating as far back as 50,000 years. ${ }^{5}$

Although lime plaster, based on $\mathrm{CaCO}_{3}$, is not a biological material, it offers many of the same benefits as organic biological materials for radiocarbon dating. ${ }^{6,7}$ First, it is clearly an anthropogenic material that indicates intentional human activity. Second, and perhaps most importantly, burnt lime $(\mathrm{CaO})$ recarbonates with carbon dioxide from the atmosphere at the time of burning, which means that the radiocarbon levels of a pristine plaster will be consistent with the time at which the plaster was first formed. Therefore, although lime plaster shares a simple chemical composition and crystal structure with many other geogenic and biogenic calcium-carbonate-based materials, its isotopic composition is quite distinct.

It is surprising that, given the possible archaeological benefits of dating lime plasters, there have been relatively few successful attempts. In fact, a handful of existing studies has demonstrated that 
plaster dating is quite problematic. One of the major impediments is that unburnt limestone, added either intentionally to increase bulk or unintentionally due to inhomogeneous heating during preparation, causes a dilution of the ${ }^{14} \mathrm{C}$, which corresponds to artificially old dates. Furthermore, diagenesis of the plaster can change the ${ }^{14} \mathrm{C}$ levels, either higher or lower, by dissolution and contact with water that has a different isotopic composition than the plaster itself. So far, the most accurate method to date a plaster with radiocarbon is to extract short-lived charred botanical remains, like seeds, and to date those inclusions. ${ }^{8-10}$ Unfortunately, these remains are not always present. ${ }^{11}$ In other cases, the remains that are present are from a long-lived species that is unsuitable for precise dating, or they are badly preserved and disintegrate during the sample pretreatment prior to dating.

Can materials science methods be used to improve radiocarbon dating strategies to tell whether a plaster is in pristine condition and good for dating? We discuss in this article an overview of the materials science issues involved in high-temperature calcium carbonate formation and diagenesis that are relevant for radiocarbon dating. This has been an area of research focus at an international level for several decades, yet still many challenges need to be addressed. Our focus in this overview is on the recent progress made to develop better strategies for screening plaster samples, based on material characterization techniques, to identify candidates that are suitable for radiocarbon dating.

\section{AN INTRODUCTION TO LIME PLASTER}

Lime plaster and all of its variations (including mortar, concrete, and cement) are general coverings. Lime plaster forms in a multistep calcination and recarbonation process. ${ }^{12,13}$ When calcium carbonate $\left(\mathrm{CaCO}_{3}\right)$ is heated to temperatures above $750^{\circ} \mathrm{C}$, it decomposes to calcium oxide $(\mathrm{CaO}$, lime $)$ by the release of $\mathrm{CO}_{2}$. Upon exposure to ambient humidity, a thin layer of $\mathrm{Ca}(\mathrm{OH})_{2}$ (portlandite) encases the $\mathrm{CaO}$. This hydroxide layer can absorb atmospheric $\mathrm{CO}_{2}$ to form $\mathrm{CaCO}_{3}$ once again. The $\mathrm{Ca}(\mathrm{OH})_{2}$ formation process can be accelerated very dramatically by mixing water with the lime, in a process called slaking, to yield a paste that is easily poured and spread. As this mixture dries, it recarbonates absorbing atmospheric $\mathrm{CO}_{2}$ that has been dissolved in the slaking water and converts to $\mathrm{CaCO}_{3}$. This high temperature calcination reaction and subsequent recarbonation are summarized in Eqs. 1 and 2 below:

$$
\begin{gathered}
\mathrm{CaCO}_{3} \text { (limestone) } \stackrel{750^{\circ} \mathrm{C}}{\longrightarrow} \mathrm{CaO}+\mathrm{CO}_{2} \\
\mathrm{CaO} \stackrel{\text { water }}{\longrightarrow} \mathrm{Ca}(\mathrm{OH})_{2} \stackrel{\mathrm{CO}_{2}}{\longrightarrow} \mathrm{CaCO}_{3}+\mathrm{H}_{2} \mathrm{O}
\end{gathered}
$$

Equations 1 and 2 illustrate a very interesting aspect of lime plaster: the reactants used to produce it have nominally the same composition and crystal structure (calcite, $\mathrm{CaCO}_{3}$ ) as the final product. What changes in the transformation from limestone to plaster is the workability of the material, as well as its crystallinity and isotopic composition.

In general, lime plasters are composite materials that include aggregates or other components that add bulk to the plaster and minimize the volume of calcined material required. Some aggregates, such as silica-based minerals, can be heated together with the limestone or added during the slaking phase of the production process to produce hydraulic plaster, which dramatically changes the curing process of the plaster by allowing it to harden under water. ${ }^{12}$ In China, reports suggest that rice was used to change the grain size, and ultimately the mechanical properties, of historical plasters. ${ }^{14}$ The curing reactions described in Eqs. 1 and 2 can change depending on the composition of its components. ${ }^{13}$

The earliest plaster is known to be in Eynan (Israel) dating back to the Natufian period, approximately 12,000-15,000 years ago. ${ }^{15,16}$ From that time period forward, plaster has been observed in archaeological contexts throughout the world, including the Far East, the Levant, Africa, Europe, Scandinavia, and the Americas. $6,9,10,14,17-20$ Plaster can serve a structural function or an aesthetic purpose in buildings, ${ }^{14}$ and it has also been used in cultic contexts as funerial coverings. ${ }^{17}$ The types of aggregates found within a plaster specimen can provide information about what materials were available to people, how they reused materials, and how advanced their knowledge of the plaster production process was. For example, burial plasters at Yiftahel (a Pre-Pottery Neolithic site in the southern Levant) were often very crude, ${ }^{21}$ while plaster floors from the same site showed a much more advanced level of craftsmanship with fine-grained layers over top of thicker layers with large aggregates of limestone and reused fine-grained plaster, ${ }^{22}$ as shown in Fig. 1.

\section{AN INTRODUCTION TO RADIOCARBON DATING}

The radiocarbon dating method has revolutionized archaeological research by assigning absolute ages to strata within an archaeological site. The method is very well understood and documented, ${ }^{1}$ and it is based on the detection and quantification of the radioactive ${ }^{14} \mathrm{C}$ concentration in relation to the concentration of its most abundant stable isotope, ${ }^{12} \mathrm{C}$. Radioactive ${ }^{14} \mathrm{C}$ is produced naturally by the interaction of cosmic rays with the terrestrial atmosphere, where it reacts rapidly with oxygen to form carbon dioxide. This ${ }^{14} \mathrm{CO}_{2}$ is the vehicle by which radiocarbon is incorporated into the biosphere and hydrosphere, through a variety of chemical processes. As long as the system remains open so that the uptake of 

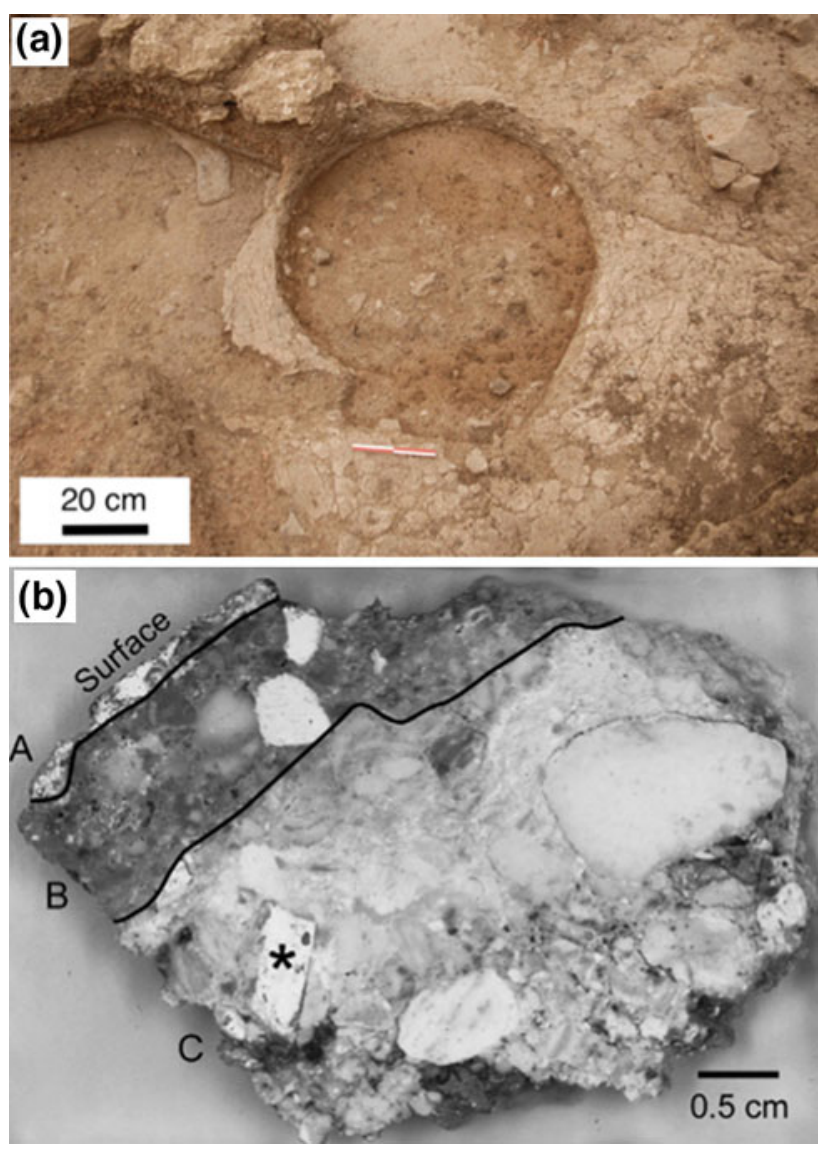

Fig. 1. (a) (color online) An in situ plaster floor at Yiftahel, a PrePottery Neolithic site in the southern Levant, with an age of $\sim 10,000$ years. This floor is cut by a large circular pit. (b) A crosssectional view of a piece of a plaster floor from Yiftahel. The thin, fine-grained surface layer $(A)$ does not have as many macroscopic geogenically sourced aggregates as are contained in the two thicker, lower layers $(\mathrm{B}, \mathrm{C})$. An asterisk marks a white rectangular inclusion that is similar in color and texture to the surface layer, and it is likely a reused piece of lime plaster. (Part (b) reproduced with permission from Elsevier Publishers based on Ref. 23).

atmospheric radiocarbon is allowed, the radiocarbon concentration will be in equilibrium. However, once this $\mathrm{CO}_{2}$ exchange is interrupted-when the plant or animal dies-then the ${ }^{14} \mathrm{C}$ concentration in the sample starts to decrease due to radioactive decay. Therefore, the measured concentration of ${ }^{14} \mathrm{C}$ in a specimen is dependent on the amount of time elapsed since carbon exchange with the atmosphere and other reservoirs stopped. By applying a simple decay law, it is possible to calculate the radiocarbon age from the measured ${ }^{14} \mathrm{C}$ concentration.

One important condition that makes radiocarbon dating possible is that the concentration of ${ }^{14} \mathrm{C}$ in the past is known very accurately. Knowledge about variations in past radiocarbon concentrations has been built by measuring radiocarbon concentrations in archives with known age, such as tree rings (dendrochronology), corals, marine, and lake sediments. A radiocarbon calibration curve has been built that correlates the measured radiocarbon age with the time elapsed. The most recent calibration curve, completed in 2009 , extends the calibration to the end limit of possible radiocarbon dating: 50,000 years ago. ${ }^{5}$

For accurate and precise radiocarbon dating of an archaeological material, not only is the analytical radiocarbon measurement method important, but also it is imperative to use sample preparation techniques that are tailored to the type of material to be dated. Furthermore, it is important to know the archaeological context in which the article was retrieved to understand how the datable object relates to the broader archaeological picture. In the case of carbonate samples produced by pyrotechnology, the context is generally very secure because such specimens are not formed during normal geological processes. ${ }^{24,25}$ However, screening the samples, especially to recognize and account for diagenetic processes, is not a simple task. ${ }^{26}$

\section{RADIOCARBON DATING APPLIED TO LIME PLASTERS AND MORTARS}

Consistent and effective radiocarbon dating of lime plasters has been sought for several decades, yet it has remained an elusive prospect. Even among early attempts, it was apparent that accurate assessments of sample purity were critical for understanding why reports of plaster dating came with mixed success. ${ }^{27,28}$ Since that time, plaster dating studies have relied heavily on other kinds of material characterization methods to help screen specimens to (I) identify what components are present in the original material, (II) identify differences in materials after separation treatments, and (III) assess when materials are adversely affected by diagenetic changes. We now discuss each of these in turn.

\section{Sample Preparation Challenges}

The main materials science challenge in lime plaster dating is that plasters are composite materials. In many cases, plasters are made with intentional and homogeneous multicomponent mixtures. Common examples include hydraulic plasters (such as pozzolana) that contain quartz or aluminosilicates, ${ }^{29,30}$ plasters that incorporate fossilized shells, ${ }^{31,32}$ or plasters containing geogenic aggregates. $^{22,33}$ Plaster can also contain incidental charcoal from the wood fuel used to produce it. ${ }^{34,35}$ Effective specimen characterization for plaster dating requires much more than just knowing what compounds and phases are present; it is also critically important to be able to differentiate among components with the same chemical composition but were produced via different formation processes. For example, calcite can appear in plaster as geogenic limestone or as biogenic shells, yet only fully calcined lime will give the correct date. Visual examples of the complexity that appears in plaster samples are shown in Figs. $1 \mathrm{~b}$ and 2a. 

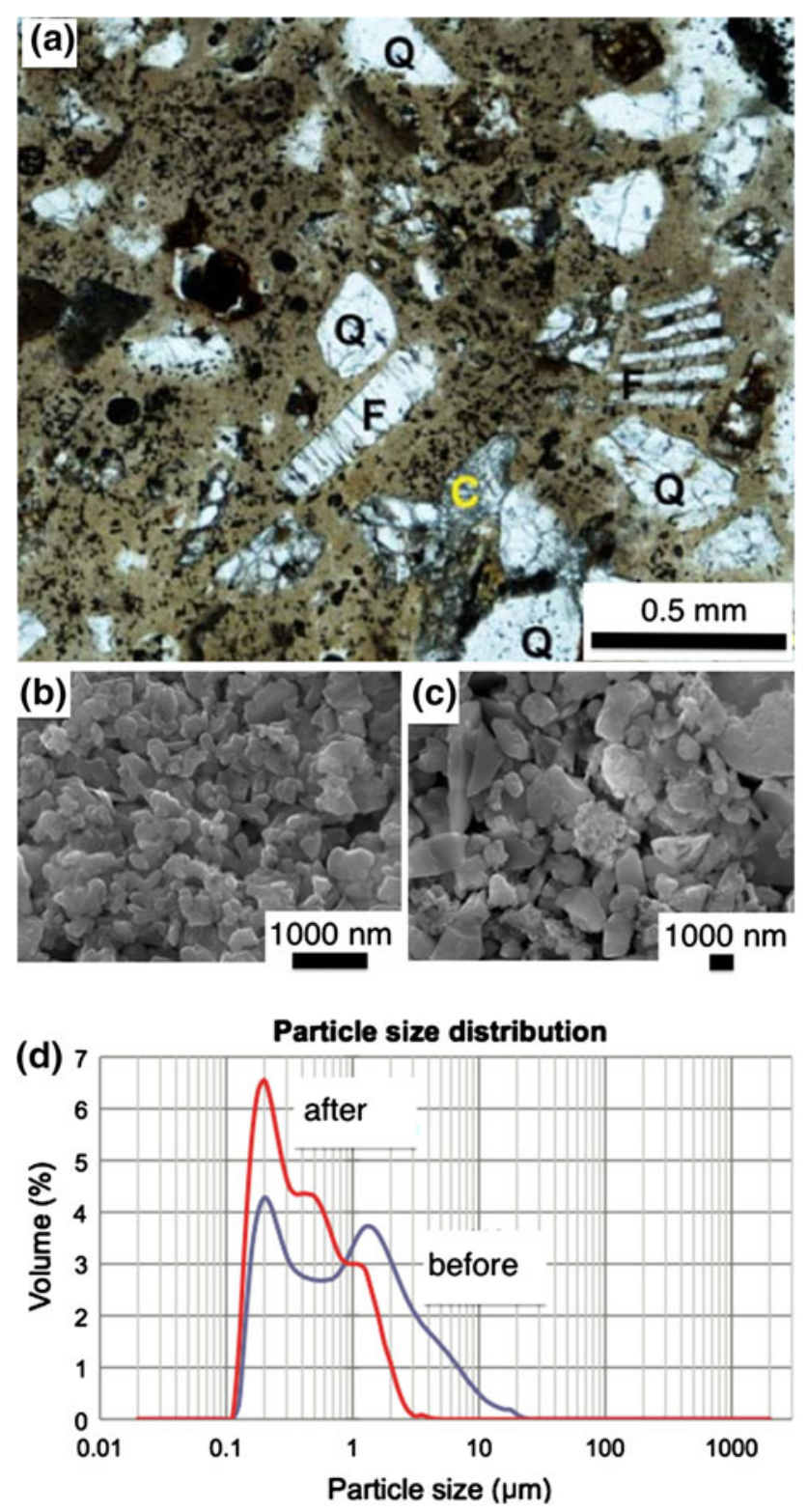

Fig. 2. (color online) (a) A representative optical micrograph illustrates the compositional and microstructural complexity of historical plasters. Here, $Q=$ quartz, $F=$ fossil remains, and $C=$ sparitic calcite. (b, c) Representative scanning electron micrographs of the same plaster, after separation into size fractions using an aqueous suspension method. The left side shows the fine fraction (average particle size $\sim 0.2 \mu \mathrm{m}$ ); the coarse fraction on the right contains detrital or mechanically fragmented inherited carbonates (particle size $\leq 2 \mu \mathrm{m}$ ). (d) Overall particle size distributions for the same plaster shown in (b) and (c). The "before" curve, corresponding to the specimen shown in (b), shows a bimodal spread with a large number of particles at small sizes $(0.2 \mu \mathrm{m})$ and coarse sizes $(1.5 \mu \mathrm{m})$ and with a tail reaching to $20 \mu \mathrm{m}$. After extraction (corresponding to the specimen shown in (c)), the distribution is skewed forward smaller sizes with a little tail reaching to only $4 \mu \mathrm{m}$. All images reproduced with permission from the Arizona Board of Regents on behalf of the University of Arizona from Ref. 36.

Separating the datable calcite fraction from everything else in a plaster is not trivial. In some cases, macroscopic physical characteristics of the plaster are a good guide. For example, large geogenic or biogenic aggregates are often distinct from a more fine grained binder; such aggregates are generally avoided for dating because they should yield artificially low (old) ${ }^{14} \mathrm{C}$ levels ${ }^{22,31}$ (see also Figs. $1 \mathrm{~b}$ and $2 \mathrm{a}$ ). On the other hand, macroscopic lumps of pure calcined lime, embedded in mortar as shown in Fig. 3, have shown promise for radiocarbon dating. ${ }^{33,37}$ Other more labor-intensive strategies have involved separating the calcitic fraction by size or by selective dissolution. ${ }^{36,38}$ An example of size fraction separations applied to an historic plaster is shown in Figs. 2b-d.

Even under normal weathering conditions, plaster will undergo diagenetic processes based on dissolution and reprecipitation. Reports have shown that different grain sizes from lime plaster samples will have different dissolution rates, with larger grains being more stable against dissolution. ${ }^{39}$ For this reason, plaster is also more prone to dissolution that geogenic calcite. This fact has been demonstrated in particle size separation experiments. ${ }^{38,39}$ Areas of the plaster that have undergone recrystallization can often be identified with optical microscopy. ${ }^{22}$ Fluorescence microscopy on optically thin cross-sections of a plaster sample will have bright regions where fulvic acid, present in ground water, has been incorporated into calcite grains. The calcite grains themselves are submicron size in as-formed plaster, but recrystallized plaster can grow much larger calcite grains that show a characteristic extinction upon viewing with crossed polarizers.

Because the recarbonation process after slaking involves the absorption of carbon from an atmospheric source, the carbon isotopic composition at the time of curing is identical to the atmospheric carbon isotope ratios. Tracking changes in the stable carbon isotope ratios $\left({ }^{13} \mathrm{C} /{ }^{12} \mathrm{C}\right)$ can be one of the most powerful ways to track plaster diagenesis. ${ }^{40,41}$ Fresh plaster that has all of its carbon incorporated from atmospheric sources has slightly less ${ }^{13} \mathrm{C}$ than the geogenic limestone from which it is made. Since this geogenic stable carbon isotope ratio is constant throughout the world, it is common to report the lighter plaster mass as a fractional percent, in parts per thousand $\left(\delta^{13} \mathrm{C}\right)$, relative to the standard geogenic value. ${ }^{1}$ Represented in this way, fresh plaster has a $\delta^{13} \mathrm{C}$ value of -21 , limestone has a $\delta^{13} \mathrm{C}$ value of 0 , and ancient plasters have values in between. ${ }^{40,41}$ It is common to see depth-dependent carbon isotope fractionation due to the normal plaster-hardening process that occurs over a time span of many years. ${ }^{22,38}$ Depth-dependent fractionation has also been observed in fire-damaged mortars. ${ }^{18}$ The stable isotope composition of the plaster would also change after dissolution and recrystallization that involved exchange of carbon from water.

\section{Interpretation}

To determine whether the sample treatment procedures work well to isolate the desired datable carbon fraction, it is advantageous to compare the 
radiocarbon dates from plasters with other dating information, such as radiocarbon dates from stratigraphically associated objects or by comparing with historical records. ${ }^{42}$ Some studies have focused on dating successive size or dissolution fractions of a plaster to identify which fraction has a date that best corresponds to the expected date. $18,38,43,44$

An intriguing possibility for future studies is to use spatial variations in radiocarbon levels to track environmental effects that have triggered different levels of diagenesis in plaster and other materials. In this sense, variations in radiocarbon levels could serve as a tracer for diagenetic vectors and processes, rather than solely as a means of getting "the right date".,22

\section{AN EXTENDED EXAMPLE: CRYSTALLINITY AS A SCREENING TOOL}

Since dissolution and reprecipitation are the primary plaster diagenesis processes, it is not surprising that assessments of structural changes can help identify specimens that are unaltered and appropriate for dating. Structural changes due to lime plaster diagenesis are not generally associated with changes in composition or phase but rather involve changes in crystallinity, which is the degree of three-dimensional periodic order present in the material. Recent studies have shown that crystallinity changes, monitored through Fourier transform infrared (FTIR) spectral features, may be an effective screening technique to eliminate samples that have undergone diagenesis. ${ }^{22}$

The initial plaster formation process (Eqs. 1 and 2) yields calcium carbonate grains that are crystalline but much smaller than typical limestone grains. X-ray diffraction measurements show broader diffraction peaks for plaster compared to those for limestone, ${ }^{45}$ which is consistent with smaller grain sizes and poorer long-range periodicity. Thus, the most well-preserved plaster samples are those that have the poorest long-range periodicity.
FTIR spectroscopy has emerged as a very practical tool to screen for well-preserved plasters. ${ }^{23,45,46}$ In general, FTIR peaks will broaden when there are structural differences that influence the local coordination environment in a material. This has been well explored in the case of calcium carbonates through coordinated experimental and theoretical investigations. ${ }^{47}$ However, this structure-induced peak broadening can easily be overwhelmed by broadening from other sources, such as scattering and particle size effects. ${ }^{45}$ The magnitudes of these latter peak broadening factors will vary depending on the details of the measurement geometry and the subsequent sample preparation.

Recently, a simple strategy was demonstrated for extracting information due to structure-induced broadening from calcite-based materials, including plasters. ${ }^{23,45,46}$ The approach involves transmission FTIR measurements on calcite samples that are diluted in an infrared-transparent matrix $(\mathrm{KBr})$. These calcite- $\mathrm{KBr}$ pellets are reground and remeasured several times to cover a broad range of particle size and distribution conditions. By comparing relative peak heights within a single spectrum (such as the representative FTIR shown in Fig. 4a) and plotting these ratios for differently ground samples, a clear and repeatable trend emerges that makes well-preserved (poorly ordered) plaster quite distinct from geogenic (highly crystalline) calcite sources. $^{23,46}$ The extent of calcium carbonate crystallinity has been described in terms of a peak ratio index (nu ratio ${ }^{46}$ ), as well as by comparing the peak ratio "grinding curves." ${ }^{23}$ Simulations show that these peak ratio changes are what is expected for decreasing particle sizes in the transparent matrix due to repeated grinding, and density functional theory calculations have shown that these spectroscopic peak width changes are consistent with a greater deviation in local order in plasters. ${ }^{45}$

The grinding curve method has been used, in conjunction with micromorphology studies, to screen
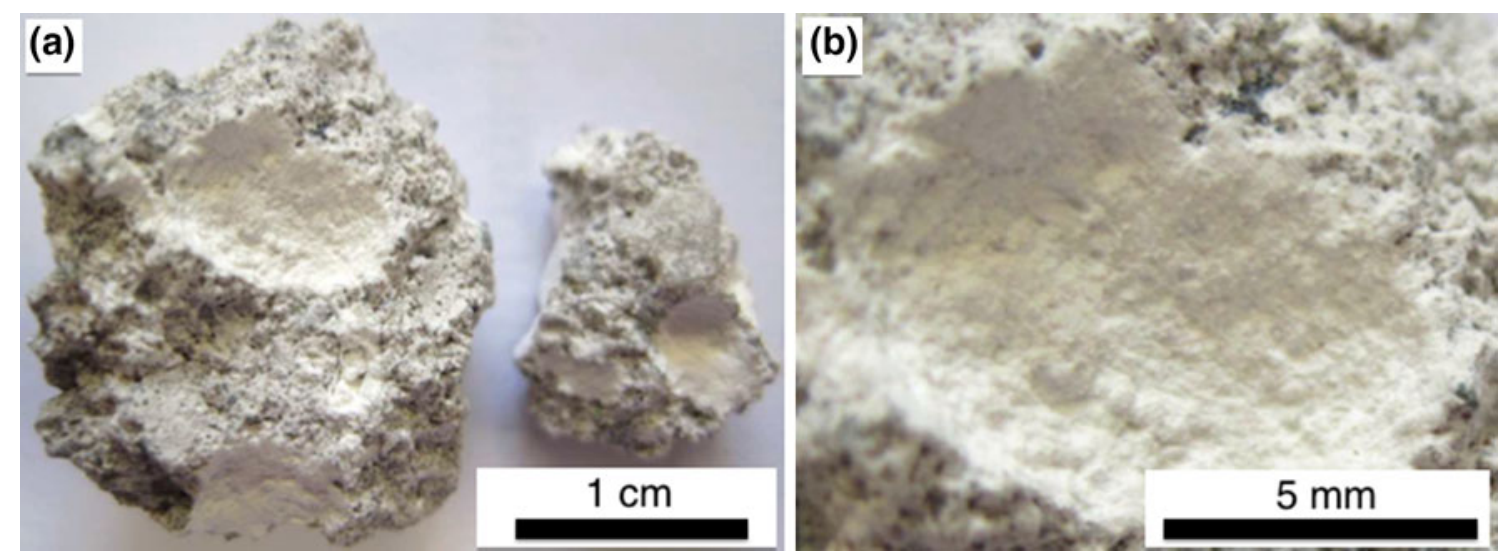

Fig. 3. (color online) (a) Photograph of macroscopic lime lumps embedded in mortar, and (b) an enlarged view of the same mortar piece. Image reproduced according to the terms of Creative Commons from Ref. 37. 
archaeological plasters to identify good candidates for radiocarbon dating. ${ }^{22}$ In this case, the authors show that an atomic disorder signature that is most similar to modern plaster, as detected from grinding curves based on FTIR spectra (Fig. 4b), produced a ${ }^{14} \mathrm{C}$ date closest to the expected age. This shows promise for using crystallinity assessment from FTIR spectra and perhaps by other structural characterization methods, to identify plaster specimens that have experienced diagenetic changes.

\section{THE IMPORTANCE OF ARCHAEOLOGICAL CONTEXT}

The ultimate goal of characterizing the material properties of an archaeological lime plaster is to extract clues about how ancient peoples lived. Because of this, the archaeological context in which a material is found is of paramount importance when trying to interpret the meaning and validity of its radiocarbon levels. ${ }^{2,3}$ Establishing a good archaeological
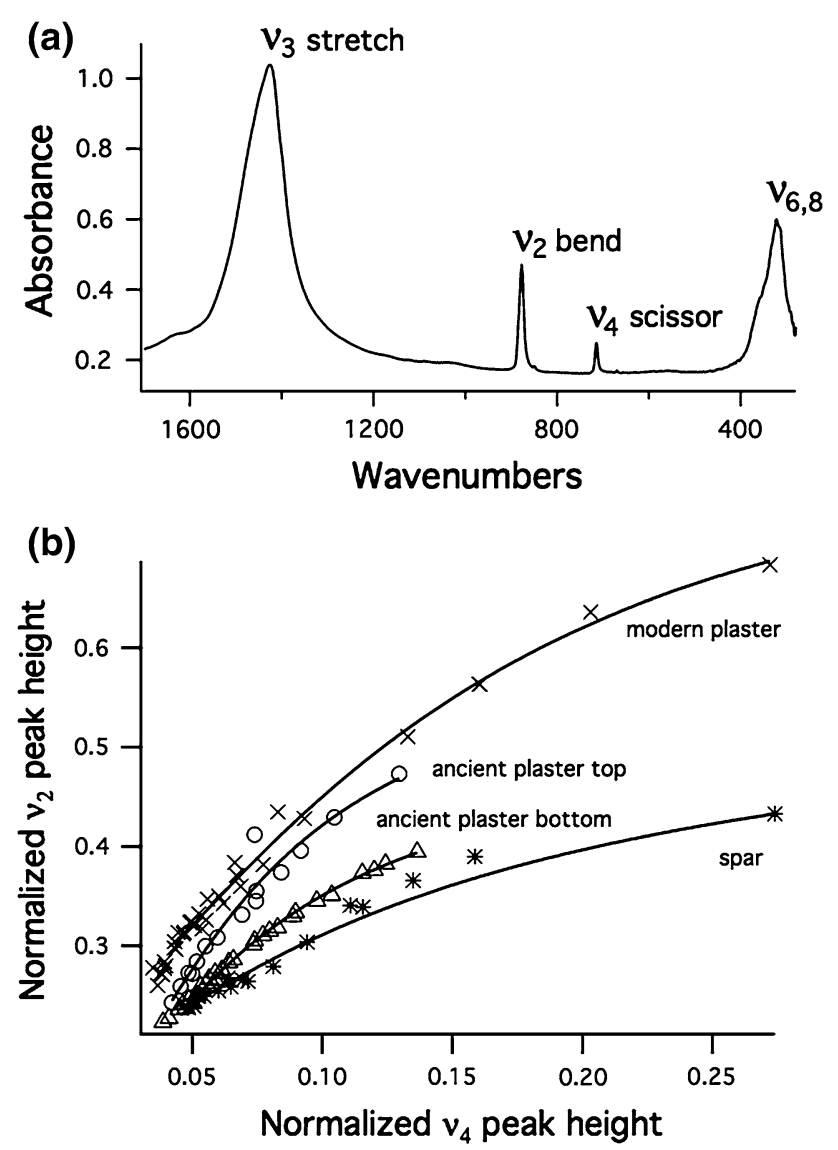

Fig. 4. (a) An FTIR spectrum of calcite shows absorbance peaks that are characteristic of different carbonate vibrational modes, including stretch-, bend-, and scissor-type modes. (b) When the height of the scissor-type $\left(v_{4}\right)$ mode or the bend-type $\left(v_{2}\right)$ mode is normalized to the height of the stretch $\left(v_{3}\right)$ mode (within the same spectrum), a plot of these ratios gives a clear and repeatable trend that makes well-preserved (poorly ordered) plaster quite distinct from geogenic (highly crystalline) calcite sources. (Figures are based on data originally presented in Ref. 22). context must be done carefully during the excavation process, and it requires comprehensive sampling of sediments and other material throughout the area of interest to establish standards and to identify changes that are indicative of human use, or of destruction events such as fires. ${ }^{26}$ This requires careful planning and strategizing among all excavation participants because it is not feasible to retain all excavated material, nor is it desirable to undertake time-consuming sample analyses that cause prohibitively long delays in the excavation process.

Although many times it appears easy to identify plaster living surfaces and other human-built structures by eye, it is important to recognize that misidentification of a plaster floor can dramatically change the archaeological interpretation. This was demonstrated dramatically in the case of sediment strata at Tel Dor (Israel), where FTIR spectroscopy measurements showed that dense concentrations of white phytoliths (silica), indicative of a grain storage area, were layered in between thin white plaster floors, which are indicative of human living surfaces. ${ }^{48}$ In this case, a quick measurement that identified the difference between silica and calcium carbonate opened a new line of archaeological investigation and interpretation.

There are other instances where the archaeological material characterization strategies must be more nuanced. It is difficult to distinguish plaster from other sources of calcite that can be found in archaeological settings, such as crushed limestone, chalk surfaces, or ash layers. As mentioned earlier, the challenge here is that all of these materials are calcite-based with nearly identical compositions and crystal structures. FTIR peak comparisons have been used quite successfully to differentiate plasters and ash from geogenic (chalk and limestone) and

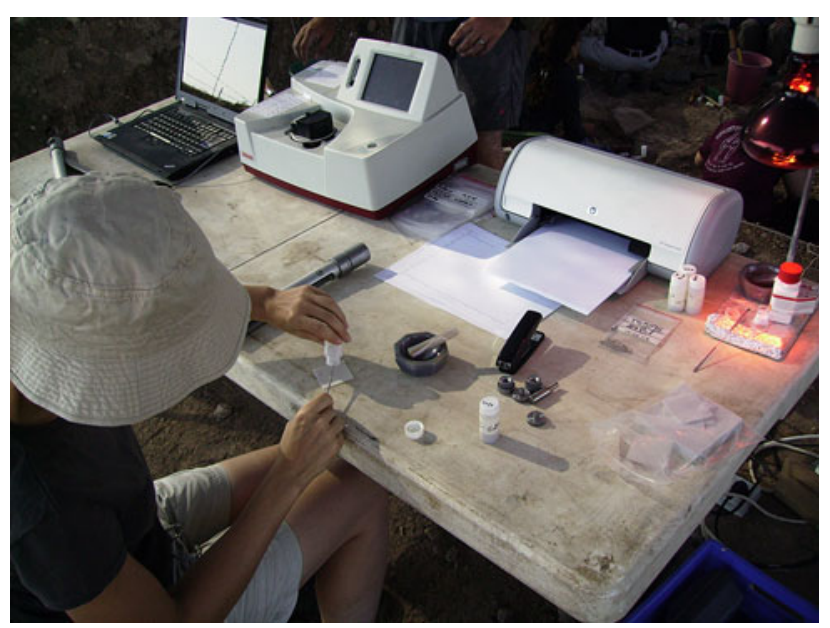

Fig. 5. (color online) FTIR spectroscopic measurements can be an expedient in-field diagnostic method. As shown here, the samples can be collected, prepared, and measured at an archaeological excavation site. 
biogenic (shells) forms of calcite. ${ }^{23,45,46}$ This approach has been recognized as transformative in the application of scientific archaeology because it can be used quickly, in the field, to get the information during the excavation process (Fig. 5 and Refs. 26 and 49).

In terms of pyrotechnological materials with secure archaeological context, it is important to mention that plaster is not the sole option to pursue as a candidate for radiocarbon dating. Wood ash is another calcite-based archaeological material whose ${ }^{14} \mathrm{C}$ levels reflect its age, but it is much less studied. Ash-based calcite forms from the decomposition of calcium oxalate $\left(\mathrm{CaC}_{2} \mathrm{O}_{4}\right)$ that is present in plants. Similar to plaster, ash has been shown to have different stable carbon and oxygen isotopic composition from the original oxalate depending on the burning temperature. ${ }^{50}$ This signature can be used to understand the diagenesis of ash or its mixing with other carbonates in the archaeological record. Moreover, offsets to the ${ }^{14} \mathrm{C}$ and $\delta^{13} \mathrm{C}$ levels have been observed when comparing modern ash produced with millenium-aged wood from archaeological contexts. ${ }^{51}$ The mechanism for these isotopic changes in ash is not yet understood, which makes exploring the formation and diagenesis of calcitic ash an interesting direction for further study.

\section{CONCLUSIONS}

Lime plaster remains one of the best candidate materials for establishing firm and secure dates in the archaeological record for human living surfaces and installations. Nevertheless, a reliable and reproducible method to define and identify a pristine plaster has not yet been established. Most reports that attempt plaster dating shows that ${ }^{14} \mathrm{C}$ levels in many ancient and historical plasters exhibit offsets relative to levels expected, based on comparisons with dates of nearby objects. These offsets can often reasonably be explained due to contamination by geogenic carbonates or by diagenetic processes such as dissolution and recrystallization. However, the ultimate goal is to do much more than just explain why the dates do not agree. A much more powerful approach is to relate radiocarbon concentrations with environmental, production, and/or diagenetic conditions in which the plaster existed. This is a tall order because it will require development of tailored sample screening and separation conditions for different types of plaster. Past research has clearly shown that different plaster additives and inclusions create unique materials analysis challenges.

Unlike many current materials science challenges wherein the focus is on controlling synthesis conditions to make an end product with certain desired properties, the materials science challenge of archaeological plasters is in working backward from the product to try to deduce the original composition, and the diagenetic changes that have occurred in the material over time, that could provide the keys necessary for an accurate interpretation of its ${ }^{14} \mathrm{C}$ level. In this sense, archaeological plasters offer a stimulating and intriguing opportunity to the materials science community to explore how and why isotopic composition can change in a material during its production, use, and diagenesis.

\section{ACKNOWLEDGEMENTS}

Funding from Natural Science and Engineering Resource Council (NSERC) Canada (KMP). We also acknowledge the Kimmel Center for Archaeological Science at the Weizmann Institute of Science for providing an exciting meeting point for science and archaeology.

\section{REFERENCES}

1. S. Bowman, Radiocarbon Dating. (Berkeley: University of California Press, 1990).

2. E. Boaretto, Isr. J. Earth Sci. 56, 207 (2007).

3. E. Boaretto, Radiocarbon 51, 275 (2009).

4. P. Vandiver, Annu. Rev. Mater. Res. 31, 373 (2001).

5. P. Reimer et al., Radiocarbon 51, 1111 (2009).

6. J. Heinemeier, H. Jungner, A. Lindroos, A. Ringbom, T. von Konow, and N. Rud, Nucl. Instr. Methods Phys. Res. B 123, 487 (1997).

7. J. Hale, J. Heinemeier, L. Lancaster, A. Lindroos, and A. Ringbom, Am. Scientist 91, 130 (2003).

8. M. Van Strydonck, K. Van Der Borg, A.F.M. De Jong, and E. Keppens, Radiocarbon 34, 873 (1992).

9. A. Frumkin, A. Shimron, and J. Rosenbaum, Nature 425, $169(2003)$.

10. L.V. Rutgers, K. van der Borg, and A.F.M. de Jong, I. Poole. Nature 436, 339 (2005).

11. A.W.G. Pike, D.L. Hoffmann, M. García-Diez, P.B. Pettitt, J. Alcolea, R.D. Balbín, C. González-Sainz, C. de las Heras, J.A. Lasheras, R. Montes, and J. Zilhão, Science 336, 1409 (2012).

12. E. Borelli, ARC Laboratory Handbook. (Rome: International Centre for the Study of the Preservation and Restoration of Cultural Property, 1999).

13. H.J.P. Brocken, N.M. van der Pers, and J.A. Larbi, Mater. Struct. 33, 634 (2000).

14. F. Yang, B. Zhang, and Q. Ma, Acct. Chem. Res. 43, 936 (2010).

15. W.D. Kingery, P. Vandiver, and M. Prickett, J. Field Archaeol. 15, 219 (1988).

16. F. Valla, H. Khalaily, H. Valladas, E. Kaltnecker, F. Bocquentin, T. Cabellos, and D.E. Bar-Yosef Mayer, J. Isr. Prehist. Soc. 37, 135 (2007).

17. I. Kuijt, and N. Goring-Morris, J. World Prehist. 16, 361(2002).

18. A. Lindroos, L. Regev, M. Oinonen, A. Ringbom, and J. Heinemeier, Radiocarbon 54, 915 (2012).

19. S. Felder-Casagrande, H.G. Wiedemann, and A. Reller, J. Thermal Anal. 49, 971 (1997).

20. C. Weiss, and I. Gerlach, Archaeol. Anthropol. Sci. 1, 87(2009).

21. I. Milevski, H. Khalaily, N. Getzov, and I. Hershkovitz, Paléorient 34, 37 (2008).

22. K.M. Poduska, L. Regev, F. Berna, E. Mintz, I. Milevski, H. Khalaily, S. Weiner, and E. Boaretto, Radiocarbon 54, 887 (2012).

23. L. Regev, K.M. Poduska, L. Addadi, S. Weiner, and E. Boaretto, J. Archaeol. Sci. 37, 3022 (2010).

24. F. Berna, A. Behar, R. Shahack-Gross, J. Berg, E. Boaretto, A. Gilboa, I. Sharon, S. Shalev, S. Shilstein, N. YahalomMack, J.R. Zorn, and S. Weiner. J. Archaeol. Sci. 34, 358 (2007).

25. F. Berna, P. Goldberg, Isr. J. Earth Sci. 56, 107 (2008). 
26. S. Weiner, Microarchaeology: Beyond the Visible Archaeological Record. (Cambridge University Press, Cambridge, 2010).

27. J. Labeyrie, and G. Delibrias, Nature 201, 742 (1964).

28. M.S. Baxter, and A. Walton, Nature 225, 937 (1970).

29. A. Lindroos, J. Heinemeier, A. Ringbom, F. Brock, P. Sonck-Koota, M. Pehkonen, and J. Suksi, Comm. Hum. Litt. 128, 214 (2011).

30. G. Hodgins, A. Lindroos, A. Ringbom, J. Heinemeier, and F. Brock, Comm. Hum. Litt. 128, 209 (2011).

31. M. Van Strydonck, M. Dupas, and M. Dauchot-Dehons. Radiocarbon 28, 702 (1986).

32. T. Goslar, D. Nawrocka, and J. Czernik, Radiocarbon 51, 987(2009).

33. G.L.A. Pesce, R.J. Ball, G. Quarta, and L. Calcagnile, Radiocarbon 54, 933 (2012).

34. R. Berger, Radiocarbon 34, 880 (1992).

35. A.M. Wyrwa, T. Goslar, and J. Czernik, Radiocarbon 51, 471 (2009).

36. L. Angel Ortega, M. Cruz Zuluaga, A. Alonso-Olazabal, X. Murelaga, M. Insausti, and A. Iba-ez-Etxeberria, Radiocarbon 54, 933 (2012).

37. G.L. Pesce, R.J. Ball, Radiometric Dating, InTech: Available from: http://www.intechopen.com/books/radiometric-dating/ dating-of-old-lime-based-mixtures-with-the-pure-lime-lumpstechnique, 2012.

38. A. Lindroos, J. Heinemeier, Å. Ringbom, M. Braskén, and Á. Sveinbjörnsdótter, Radiocarbon 49, 47 (2007).
39. E. Sonninen, and H. Jungner, Radiocarbon 43, 271 (2001).

40. C. Pachiaudi, J. Marechal, M. Van Strydonck, M. Dupas, and M. Dauchot-Dehon, Radiocarbon 28, 691 (1986).

41. M. Van Strydonck, M. Dupas, and E. Keppens, Radiocarbon 31, 610 (1989).

42. M.M. Langley, S.J. MaLoney, Å. Ringbom, J. Heinemeier, and A. Lindroos, Comm. Hum. Litt. 128, 242 (2011).

43. D. Nawrocka, T. Goslar, A. Pazdur Materials, Technologies and Practice in Historic Heritage 279 Structures. (Amsterdam: Springer, 2010).

44. D. Michalska, A. Pazdur, J. Czernik, M. Szczepaniak, and M. Zurakowska, Geochronometria 40, 33 (2013).

45. K.M. Poduska, L. Regev, E. Boaretto, L. Addadi, S. Weiner, L. Kronik, and S. Curtarolo, Adv. Mater. 23, 550 (2011).

46. V. Chu, L. Regev, S. Weiner, and E. Boaretto, J. Archaeol. Sci. 35, 905 (2008).

47. R. Gueta, A. Natan, L. Addadi, S. Weiner, K. Refson, and L. Kronik, Angew. Chem. Int. Ed. 46, 291 (2007).

48. R. Shahack-Gross, R.-M. Albert, A. Gilboa, O. NagarHilman, I. Sharon, and S. Weiner, J. Archaeol. Sci. 32, 1417 (2005).

49. H. Watzman, Nature 468, 614 (2010).

50. R. Shahack-Gross, and A. Ayalon, J. Archaeol. Sci. 40, 570(2013).

51. L. Regev, E. Eckmeier, E. Mintz, S. Weiner, and E. Boaretto, Radiocarbon 53, 117 (2011). 